\title{
Diversidade e ocorrência temporal da anurofauna (Amphibia, Anura) em São José dos Pinhais, Paraná, Brasil
}

\author{
Carlos E. Conte \& Denise de C. Rossa-Feres
}

Departamento de Zoologia e Botânica, Universidade Estadual Paulista. Rua Cristóvão Colombo 2265, 15054-000 São José do Rio Preto, São Paulo, Brasil. E-mail: kadu_conte@yahoo.com.br; denise@ibilce.unesp.br

\begin{abstract}
Diversity and seasonal occurrence of anurans in São José dos Pinhais, Paraná, Brazil. The Atlantic Forest is the biome with the largest biodiversity and endemism rate of anuran amphibians in the world. However, information on natural history and patterns of occurrence are still unknown for most of the species that occur in this biome. In this study the diversity and the seasonal occurrence of anuran amphibians were determined in an ecotone area between Atlantic Forest and Araucaria Forest, in the southeastern of Paraná state. In the survey, accomplished from January 2003 to May 2004, 34 species from five families were registered: Bufonidae (two species), Hylidae (17 species), Leptodactylidae (13 species), Microhylidae (one species) and Ranidae (one species). The species richness is one of the largest of Paraná state and eight of the nine studied sites presented high diversity of species. The fact that the studied area is located in an ecotone supports the occurrence of typical species from two physiognomies. Besides, an additional hypothesis to explain this great diversity is the intermediate disturbance due to the deforestation that occurred until thirty years ago, which made the occurrence of some typical species from open areas possible. The largest number of species (48\%) occurred during the rainy season, however, the proportion of annual species was great $(25 \%)$, similar to the one found in regions with wet tropical climate (30\%). The similarity in species composition among nine localities in Atlantic Forest in Paraná State was associated to the vegetal physiognomy of the studied areas.

KEY WORDS. Atlantic Rainforest; community ecology; species richness.
\end{abstract}

RESUMO. A Floresta Atlântica é o bioma com a maior diversidade e taxa de endemismo de anfíbios anuros do mundo. Entretanto, informações sobre a história natural e os padrões de ocorrência das espécies são, em grande parte, ainda desconhecidas para esse bioma. No presente estudo, a diversidade e a ocorrência temporal de espécies de anuros foram determinadas em área de ecótono entre Floresta Ombrófila Densa e Floresta Ombrófila Mista no estado do Paraná, sul do Brasil. No levantamento, realizado entre janeiro de 2003 e maio de 2004, foram registradas 34 espécies de cinco famílias: Bufonidae (duas espécies), Hylidae (17 espécies), Leptodactylidae (13 espécies), Microhylidae (uma espécie) e Ranidae (uma espécie). A riqueza registrada é uma das maiores do Paraná e oito, dos nove hábitats amostrados, apresentaram alta diversidade de espécies. Isso pode ser decorrente do fato da área estudada estar localizada em região de ecótono, o que favoreceu a ocorrência de espécies típicas de cada formação vegetal. Além disso, uma hipótese adicional é a do distúrbio intermediário, decorrente do desmatamento ocorrido até trinta anos atrás, que possibilitou a ocorrência de algumas espécies típicas de áreas abertas. Machos da maioria das espécies ( $48 \%$ ) vocalizaram no período chuvoso e quente do ano, mas a proporção de espécies anuais (25\%) foi grande, semelhante à encontrada em regiões com clima tropical úmido (30\%). A similaridade na composição de espécies de nove localidades no Paraná foi associada à fisionomia vegetal das áreas amostradas.

PALAVRAS CHAVE. Ecologia de comunidades; Floresta Atlântica; riqueza de espécies.

Diversos estudos realizados nas últimas décadas revelaram que a região neotropical abriga a mais rica fauna de anfíbios anuros do mundo (e.g. Duellman 1978, 1990, Heyer et al. 1990), sendo a Floresta Atlântica o bioma com a maior diversidade e taxa de endemismo (Duellman 1999). Atualmente, este ecossistema está ameaçado por grandes concentrações urbanas e pólos industriais (EMBrapa 1996), resultando num cenário lastimável de devastação, que reduziu a menos de 5\% sua área original (Fundação SOS Mata AtlânTICA 1998). Por estes motivos, a Floresta Atlântica é considerada um dos 25 hotspots, regiões mais ricas em biodiversidade do planeta e, ao mesmo tempo, mais ameaçadas (WILSON 1988, MYERS et al. 2000).

Revista Brasileira de Zoologia 23 (1): 162-175, março 2006 
O desmatamento e a fragmentação florestal afetam negativamente a fauna regional (BeEbee 1996, Alford \& Richards 1999), em especial algumas espécies de anuros que mantêm estreita e complexa relação de interdependência com ambientes florestais, levando a alterações na abundância populacional e na riqueza de espécies (Tocher et al. 1997). Agravante é que, para a maioria dos táxons da Floresta Atlântica há uma carência incontestável de estudos bionômicos (HADDAD \& SAZIMA 1992, Pombal Jr. \& Gordo 2004), o que dificulta a tomada de decisões conservacionistas eficazes para o grupo e seu bioma.

No Paraná, sul do Brasil, a diversidade de anuros também permanece pouco conhecida (Bernarde \& Machado 2000). Embora 120 espécies estejam registradas (SEgala \& Langone 2004), os estudos de inventário e ecologia estão concentrados em poucas localidades, especialmente na região norte e ao longo da Bacia do rio Tibagi (e.g. Machado \& Bernarde 2002). Com isso, são várias as lacunas na distribuição geográfica das espécies, havendo muitas áreas de dimensões consideráveis onde nenhum conhecimento foi ainda gerado. Particularmente no sudeste do Paraná, pouco se conhece sobre a ocorrência e a distribuição das espécies de anuros. Assim, o presente estudo foi desenvolvido com os objetivos de realizar o levantamento da anurofauna, determinar a diversidade e a ocorrência sazonal das espécies em nove corpos d'água e arredores, em área de Mata Atlântica no município de São José dos Pinhais, sudeste do Paraná.

\section{MATERIAL E MÉTODOS}

\section{Área de estudo}

$\mathrm{O}$ estudo foi desenvolvido na localidade de Serro e Ge-

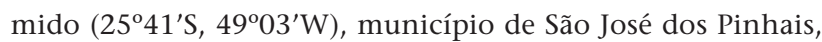
porção leste do primeiro planalto paranaense, a $50 \mathrm{~km}$ de Curitiba (Fig. 1). A área possui altitude média de $980 \mathrm{~m}$, sendo geologicamente constituída pelo mesmo sistema estrutural da Serra do Mar (MAACK 1981). O clima é subtropical úmido mesotérmico ou Cfb de Köppen, com verões frescos e ocorrência de geadas severas e freqüentes. A média de temperatura nos meses mais quentes é inferior a $22^{\circ} \mathrm{C}$ e a dos meses mais frios é inferior a $18^{\circ} \mathrm{C}$ (FerReIRA 1996). A precipitação anual varia de 1.400 a $1.700 \mathrm{~mm}$, com concentração de chuvas no período de outubro a março, mas sem estação seca definida (Paraná 1987).

Fitogeograficamente, a área de estudo encontra-se em região de ecótono entre a Floresta Ombrófila Densa (FOD) e a Floresta Ombrófila Mista (FOM). Relatos de antigos moradores da região atestam que, até a década de 70, ocorreu exploração de madeiras nobres como a canela (Ocotea sp.), o cedro (Cedrella fissilis Vell.) e a extração dos galhos da erva-mate (Ilex paraguariensis A. St.-Hil.), para o comércio de chá. A região conta, portanto, com cerca de trinta anos de recuperação e, atualmente, a principal atividade é o estabelecimento de chácaras utilizadas para lazer, com pouca interferência nas áreas florestadas.

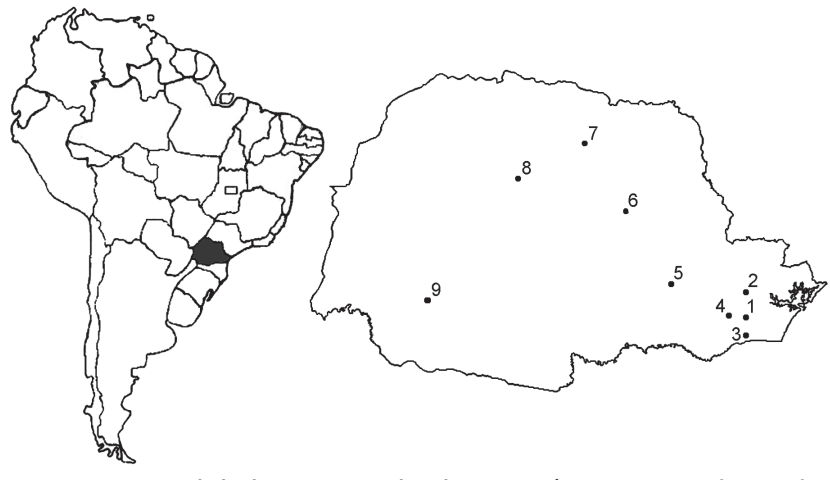

Figura 1. Localidades no estado do Paraná, cuja anurofauna foi inventariada: (1) São José dos Pinhais (presente estudo), (2) Quatro Barras, (3) Tijucas do Sul, (4) Fazenda Rio Grande, (5) Palmeira, (6) Telêmaco Borba, (7) Londrina, (8) Fênix, (9) Três Barras do Paraná; sendo os dados obtidos de: $(2,5,7$ e 9) Bernarde \& MachaDO (2000), (3) CONTE \& MACHADO (2005), (4) Observação pessoal, (6) Rocha et al. (2003), (8) MIKICH \& Oliveira (2003).

Foram selecionados nove corpos d'água localizados em área aberta, no interior de floresta e em borda florestal, representando os diversos tipos de hábitats disponíveis para reprodução de anuros na área (Tab. I).

\section{Inventário da anurofauna e ocorrência sazonal}

Foram realizadas 17 visitas mensais ao campo, entre janeiro de 2003 e maio de 2004, com duração de três dias cada, totalizando cerca de $215 \mathrm{~h}$ de esforço amostral. A procura dos exemplares foi realizada pelo método de levantamento em sítio de reprodução (SCOTT JR. \& WoodWARd 1994), durante o turno noturno de vocalização das espécies, entre 20:00 e 24:00 h. Nos riachos (RF1, RF2 e RF3), como foram registradas espécies diurnas, também foram realizadas amostragens entre 15:00 e 17:00 h.

Para complementar o levantamento foi realizado busca ativa pelas espécies, que consistiu na procura dos anfíbios embaixo de troncos e pedras, no interior de bromélias e demais refúgios, bem como busca aural por espécies que vocalizam e se reproduzem distante de corpos d'água, na serapilheira ou empoleirados em arbustos e árvores no interior de floresta, como as de Eleutherodactylus Duméril \& Bibron, 1841 e Adenomera Steindachner, 1867. Exemplares testemunhos foram depositados na Coleção Científica do Departamento de Zoologia e Botânica, Universidade Estadual Paulista, Campus de São José do Rio Preto (DZSJRP), São Paulo (números: 6138 a 6320).

A abundância das espécies foi determinada pelo número de machos vocalizando, considerando a média de três estimativas, realizadas durante o percurso do perímetro de cada hábitat, ou dos trechos ao longo dos riachos. Para evitar superestimavas de abundância populacional, decorrentes da recontagem de exemplares em amostragens sucessivas, a abundância total de cada espécie foi considerada igual a do mês

Revista Brasileira de Zoologia 23 (1): 162-175, março 2006 
Tabela I. Caracterização dos hábitats amostrados em São José dos Pinhais, Paraná: (RF1) rio de leito pedregoso em interior de floresta, (RF2) continuação do rio de leito pedregoso em área plana, (RF3) córrego de leito pedregoso em interior de floresta, (RF4) riacho formado por nascente brejosa em interior de floresta, (RF5) riacho formado por nascente em interior de floresta, (TPG) tanque de piscicultura grande, (TPP) tanque de piscicultura pequeno, (PTF) poça temporária em interior de floresta, (PTA) poça temporária em área aberta. Tipos de vegetação: (Her) herbácea, (Arb) arbustiva, (Abo) arbórea.

\begin{tabular}{|c|c|c|c|c|}
\hline \multirow{2}{*}{ Hábitats } & \multirow{2}{*}{ Velocidade da água } & \multicolumn{2}{|c|}{ Vegetação no corpo d'água } & \multirow{2}{*}{ Localização } \\
\hline & & No interior & Marginal & \\
\hline RF1 & Corrente & Ausente & Her, Arb, Abo & Floresta \\
\hline RF2 & Corrente & Ausente & Her, Arb, Abo & Floresta \\
\hline RF3 & Corrente & Ausente & Her, Arb, Abo & Floresta \\
\hline RF4 & Constante troca & Ausente & Her, Arb, Abo & Floresta \\
\hline RF5 & Constante troca & Ausente & Her, Arb, Abo & Floresta \\
\hline PTF & Parada & Ausente & Her, Arb, Abo & Floresta \\
\hline PTA & Parada & Abundante & Herb & Área aberta \\
\hline TPG & Constante troca & Esparsa & Her, Abo & Borda florestal \\
\hline TPP & Constante troca & Ausente & Her, Arb & Área aberta \\
\hline
\end{tabular}

com maior abundância. Para evitar desvios na amostragem, em decorrência do turno de vocalização das espécies, a seqüência de visitas nos diversos corpos d'água era determinada por sorteio a cada visita.

\section{Análises estatísticas}

Para avaliar a eficiência da amostragem, considerando o levantamento efetuado nos corpos d'água e no interior de floresta, foi construída a curva de acumulação de espécies com base na ocorrência mensal (Colwell \& Coddington 1994, SANTos 2003). A riqueza em cada e no conjunto dos nove corpos d'água foi estimada, com base na abundância mensal das espécies, por extrapolação das curvas de acumulação pelo índice "Abundance-based Coverage Estimator" (ACE) (Colwell 2001).

A composição de espécies de São José dos Pinhais foi comparada com a de outras oito localidades do estado do Paraná com anurofauna conhecida (Fig. 1, Tab. II), pela aplicação do coeficiente de afinidade de Jaccard, com posterior análise de agrupamento ("clustering") pelo método de média não ponderada (UPGMA) (KREBS 1999).

A diversidade em cada corpo d'água foi avaliada pela aplicação dos índices de diversidade de Shannon-Wiener e de equitabilidade de Pielou (Krebs 1999). A diversidade teórica máxima (H’ máx) foi determinada segundo KreBs (1999), como o logaritmo do número total de espécies em cada corpo d'água. A diversidade foi considerada alta quando e $\geq 0,7, \mathrm{H}^{\prime} \geq 1,0$ e $\mathrm{H}^{\prime} \geq 70 \% \mathrm{H}^{\prime} \max$.

A influência do clima (temperatura, precipitação pluviométrica e umidade relativa do ar) na riqueza de espécies e na abundância de machos em atividade de vocalização foi verificada pela aplicação do coeficiente de correlação de Spearman ( $r_{s}$ ) (ZAR 1984). Os dados abióticos foram coligidos diariamente, de pluviômetro e termohigrômetro instalados no local de estudo. Os dados de temperatura, pluviosidade e umi- dade relativa do período de 1998 a 2003, foram obtidos junto ao Instituto Tecnológico SIMEPAR, que possui uma estação climatológica em Curitiba, distante aproximadamente $30 \mathrm{~km}$ do local de estudo. O período de vocalização das espécies foi classificado com base em Bertoluci \& Rodrigues (2002).

\section{RESULTADOS}

\section{Riqueza e Diversidade}

Foram registradas 34 espécies de anfíbios anuros pertencentes a cinco famílias: Bufonidae (2 espécies), Leptodactylidae (13 espécies), Hylidae (17 espécies), Microhylidae (1 espécie) e Ranidae (1 espécie) (Tab. III). Destas, Scinax fuscovarius (Lutz, 1925), Cycloramphus bolitoglossus (Werner, 1897) e Chiasmocleis leucosticta (Boulenger, 1888) não foram encontradas em atividade de vocalização. Machos de Rana catesbeiana Shaw, 1802 foram encontrados vocalizando em um açude próximo aos corpos d'água estudados. Os exemplares de Cycloramphinae ArdilaRobayo, 1979 não identificado (n.d.) representam uma espécie de Crossodactylus Duméril \& Bibron, 1841 ainda não descrita. Já Adenomera marmorata é um nome que possivelmente esteja sendo aplicado a espécies distintas (C.F.B. Haddad com. pess.).

A curva do coletor para a área amostrada, construída com base na ocorrência de espécies registradas com os dois métodos de inventário utilizados tende a uma assíntota a partir da décima quinta amostra, com o registro de 34 espécies (Fig. 2). O método de levantamento em sítio de reprodução possibilitou o registro de $79 \%$ da anurofauna local, enquanto que o método de busca ativa possibilitou o registro de 59\% das espécies (Tab. III).

As 27 espécies registradas nos nove corpos d'água representam 93\% da riqueza teórica ( $\mathrm{ACE}=29$ espécies) estimada para o conjunto de corpos d'água amostrados (Fig. 3). Em cinco dos nove corpos d'água, a diferença entre a riqueza estimada e a observada foi de menos de uma espécie e a curva do 
Tabela II. Lista das espécies nas seguintes localidades do Estado do Paraná: (SJ) São José dos Pinhais, (FR) Fazenda Rio Grande, (TS) Tijucas do Sul, (QB) Quatro Barras, (TL) Telêmaco Borba, (LO) Londrina, (FE) Fênix, (TB) Três Barras do Paraná, (PA) Palmeira. Dados originais e obtidos da literatura, conforme definido na legenda da figura 1.

\begin{tabular}{|c|c|c|c|c|c|c|c|c|c|}
\hline Espécies & S] & FR & TS & QB & $\mathrm{TL}$ & $\mathrm{LO}$ & $\mathrm{FE}$ & $\mathrm{TB}$ & PA \\
\hline Bufo abei Baldissera Jr., Caramaschi \& Haddad, 2004 & 1 & 1 & 1 & 1 & 1 & 1 & 1 & 1 & 1 \\
\hline Bufo ictericus Spix, 1824 & 1 & 1 & 1 & 1 & 1 & & & & \\
\hline Bufo schneideri Werner, 1894 & & & & & & 1 & 1 & & \\
\hline Brachycephalus pernix Pombal, Wistuba \& Bornschein, 1998 & & & & 1 & & & & & \\
\hline Hyalinobatrachium uranoscopum (Müller, 1924) & & & & & 1 & 1 & & 1 & \\
\hline Aplastodiscus albosignatus (A. Lutz \& B. Lutz, 1938) & 1 & 1 & 1 & 1 & 1 & & & & \\
\hline Aplastodiscus ehrhardti (Müller, 1924) & 1 & & & & & & & & \\
\hline Aplastodiscus perviridis Lutz in B. Lutz, 1950 & 1 & 1 & 1 & 1 & 1 & 1 & & 1 & 1 \\
\hline Bokermannohyla circumdata (Cope, 1870) & 1 & 1 & 1 & 1 & 1 & & & & \\
\hline Dendropsophus anceps (A. Lutz, 1929) & & & & & 1 & & & & \\
\hline Dendropsophus microps (Peters, 1872) & 1 & 1 & & 1 & 1 & & & & \\
\hline Dendropsophus minutus (Peters, 1872) & 1 & 1 & 1 & 1 & 1 & 1 & 1 & 1 & 1 \\
\hline Dendropsophus nahdereri (Lutz and Bokermann, 1963) & 1 & & & & & & & & \\
\hline Dendropsophus nanus (Boulenger, 1889) & & & & & 1 & 1 & 1 & & \\
\hline Dendropsophus sanborni (Schmidt, 1944) & & 1 & 1 & & 1 & & & & 1 \\
\hline Hypsiboas albopunctatus (Spix, 1824) & 1 & & 1 & 1 & 1 & 1 & 1 & & 1 \\
\hline Hypsiboas bischoffi (Boulenger, 1887) & 1 & 1 & 1 & 1 & & & & & \\
\hline Hypsiboas faber (Wied-Neuwied, 1821) & 1 & 1 & 1 & 1 & 1 & 1 & 1 & 1 & 1 \\
\hline Hypsiboas prasinus (Burmeister, 1856) & 1 & 1 & 1 & 1 & 1 & 1 & 1 & 1 & 1 \\
\hline Hypsiboas raniceps (Cope, 1862) & & & & & & 1 & 1 & & \\
\hline Hypsiboas semiguttatus (A. Lutz, 1925) & 1 & & & & 1 & & & & 1 \\
\hline Phasmahyla sp. & & & & & 1 & & & & \\
\hline Phyllomedusa tetraploidea Pombal \& Haddad, 1992 & & & & & 1 & 1 & 1 & 1 & 1 \\
\hline Phyllomedusa distincta B. Lutz, 1950 & & 1 & & & & & & & \\
\hline Scinax berthae (Barrio, 1962) & & 1 & 1 & 1 & 1 & & & & 1 \\
\hline Scinax catharinae (Boulenger, 1888) & 1 & 1 & & & 1 & & & & \\
\hline Scinax sp. (gr. catharinae) & & & & & & & & 1 & \\
\hline Scinax fuscovarius (A. Lutz, 1925) & 1 & 1 & & & 1 & 1 & 1 & 1 & 1 \\
\hline Scinax perereca Pombal Jr., Haddad \& Kasahara, 1995 & 1 & 1 & 1 & & 1 & 1 & 1 & 1 & \\
\hline Scinax rizibilis (Bokermann, 1964) & 1 & 1 & & 1 & 1 & & & & \\
\hline Scinax squalirostris (A. Lutz, 1926) & & & 1 & & 1 & & & & 1 \\
\hline Scinax uruguayus (Schmidt, 1944) & & & & & & & & & 1 \\
\hline Scinax sp. & & & & 1 & & & & & \\
\hline Scinax sp. (gr. ruber) & & 1 & & & & & & & \\
\hline Scinax sp. (gr. $x$-signatus) & & & & & 1 & & & & 1 \\
\hline Sphaenorhynchus surdus (Cochran, 1953) & 1 & 1 & 1 & 1 & 1 & & & & \\
\hline Trachycephalus imitatrix (Miranda-Ribeiro, 1926) & & 1 & & & & & & & \\
\hline Trachycephalus venulosus (Laurenti, 1768) & & & & & & 1 & 1 & 1 & \\
\hline Adenomera marmorata Steindachner, 1867 & 1 & 1 & 1 & 1 & & & & & \\
\hline Crossodactylus sp. & & & & & 1 & 1 & & 1 & \\
\hline Cycloramphinae & 1 & & & & & & & & \\
\hline Cycloramphus bolitoglossus (Werner, 1897) & 1 & 1 & 1 & & & & & & \\
\hline Eleutherodactylus binotatus (Spix, 1824) & & & & & 1 & 1 & & 1 & \\
\hline Eleutherodactylus guentheri (Steindachner, 1864) & 1 & 1 & 1 & 1 & 1 & 1 & & 1 & \\
\hline Eleutherodactylus sambaqui Castanho \& Haddad, 2000 & 1 & & & & & & & & \\
\hline
\end{tabular}


Tabela II. Continuação.

\begin{tabular}{|c|c|c|c|c|c|c|c|c|c|}
\hline Espécies & SJ & FR & TS & QB & TL & LO & $\mathrm{FE}$ & TB & PA \\
\hline Hylodes heyeri Haddad, Pombal Jr. \& Bastos, 1996 & 1 & & & & & & & & \\
\hline Leptodactylus fuscus (Schneider, 1799) & & & & & 1 & 1 & 1 & & \\
\hline Leptodactylus gracilis (Duméril \& Bibron, 1841) & & & & & 1 & & & & 1 \\
\hline Leptodactylus labyrinthicus (Spix, 1824) & & & & & & 1 & & & \\
\hline Leptodactylus mystacinus (Burmeister, 1861) & & & & & 1 & 1 & 1 & 1 & \\
\hline Leptodactylus notoaktites Heyer, 1978 & 1 & 1 & & & 1 & & & & \\
\hline Leptodactylus ocellatus (Linnaeus, 1758) & 1 & 1 & 1 & 1 & 1 & 1 & 1 & 1 & 1 \\
\hline Leptodactylus podicipinus (Cope, 1862) & & & & & & 1 & & & \\
\hline Limnomedusa macroglossa (Duméril \& Bibron, 1841) & & & & & & & & 1 & \\
\hline Odontophrynus americanus (Duméril \& Bibron, 1841) & & 1 & 1 & & 1 & 1 & 1 & 1 & 1 \\
\hline Physalaemus cuvieri Fitzinger, 1826 & 1 & 1 & 1 & 1 & 1 & 1 & 1 & 1 & 1 \\
\hline Physalaemus gracilis (Boulenger, 1883) & 1 & 1 & 1 & 1 & 1 & & & 1 & 1 \\
\hline Physalaemus olfersii (Lichtenstein \& Martens, 1856) & 1 & 1 & & 1 & & & & & \\
\hline Proceratophrys avelinoi Mercadal de Barrio \& Barrio, 1993 & & 1 & & & 1 & 1 & 1 & 1 & \\
\hline Proceratophrys boiei (Wied-Neuwied, 1825) & 1 & 1 & 1 & & & & & & \\
\hline Scythrophrys sawayae (Cochran, 1953) & 1 & & & & & & & & \\
\hline Chiasmocleis leucosticta (Boulenger, 1888) & 1 & & & & & & & & \\
\hline Elachistocleis bicolor (Guérin-Méneville, 1838) & & 1 & & & 1 & 1 & 1 & 1 & \\
\hline Rana catesbeiana Shaw, 1802 & 1 & & & & 1 & 1 & & 1 & \\
\hline Total & 34 & 32 & 23 & 22 & 39 & 27 & 19 & 23 & 19 \\
\hline
\end{tabular}

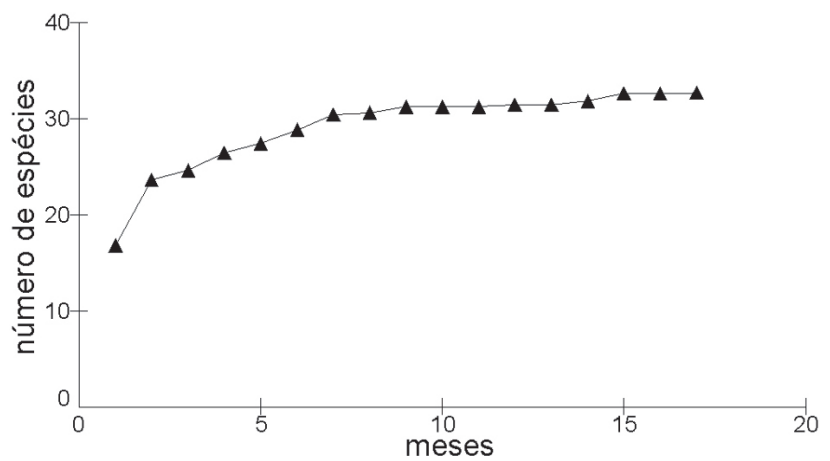

Figura 2. Curva de acumulação, baseada na ocorrência mensal de espécies no período de janeiro de 2003 a maio de 2004, no município de São José dos Pinhais, Paraná. Dados aleatorizados 1000 vezes.

estimador apresenta tendência à estabilização. Nos quatro corpos d'água restantes o método de extrapolação da curva de acumulação indica que mais espécies poderiam ser encontradas (Fig. 3).

A diversidade de espécies variou de $\mathrm{H}^{\prime}=0,35$ a $\mathrm{H}^{\prime}=2,53$ nos ambientes estudados, enquanto a equitabilidade variou de $\mathrm{e}=0,50$ a e = 0,92 (Tab. IV). Apenas no RF3 a diversidade foi baixa, equivalendo a $53 \%$ da diversidade teórica máxima. Neste ambiente ocorreram apenas duas espécies, sendo que Hylodes heyeri foi a espécie dominante, com abundância mensal variando de um a oito indivíduos, enquanto um único indivíduo de Cycloramphinae n.d. foi registrado (Tab. V), levando aos baixos valores de equitabilidade e, conseqüentemente, de diversidade (Tab. IV). Nos demais ambientes, observa-se maior riqueza e equitabilidade (Tab. IV), e conseqüentemente maior diversidade. A maior diversidade foi encontrada no TPG, ambiente com a maior riqueza de espécies (Tab. V).

A análise de similaridade (Tab. VI, Fig. 4) separou as localidades em dois grandes agrupamentos: I) formado por Palmeira, município localizado em região de Campos Naturais, Três Barras do Paraná, Londrina e Fênix, municípios inseridos no domínio da Floresta Estacional Semidecidual (FES) e Telêmaco Borba, município localizado em área de ecótono entre FOM, FES e Campos Naturais; II) formado por São José dos Pinhais e Quatro Barras, municípios localizados em área de ecótono entre FOD e FOM, Fazenda Rio Grande e Tijucas do Sul, municípios inseridos em área de domínio da FOM. Considerando a composição de espécies, a anurofauna de São José dos Pinhais foi mais semelhante com a do município Fazenda Rio Grande $\left(C_{j}=0,57\right)$ (Tab. VI, Fig. 4). A maior similaridade na composição da anurofauna foi verificada entre Londrina e Fênix $\left(C_{i}=\right.$ 0,70), com 19 espécies em comum (Tab. VI).

\section{Ocorrência sazonal}

Das 34 espécies registradas na região, 31 foram encontradas em atividade de vocalização (Fig. 5). A maioria das espé- 

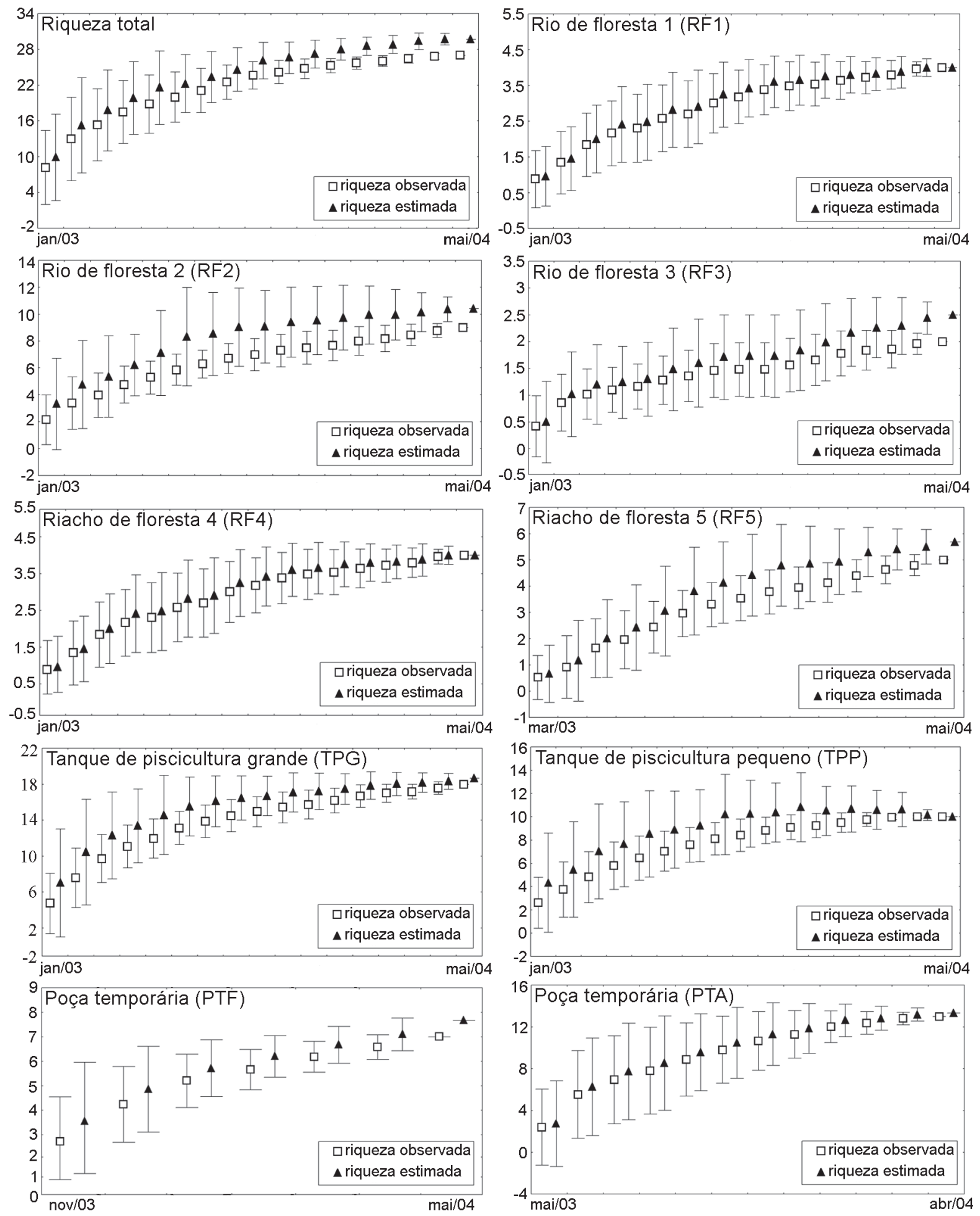

Figura 3. Curvas de riqueza observada e estimada total, e de riqueza observada e estimada em cada um dos nove corpos d'água amostrados em São José dos Pinhais, Paraná. Dados aleatorizados 50 vezes. 
Tabela III. Espécies de anfíbios anuros registrados em São José dos Pinhais, Paraná, entre janeiro de 2003 e maio de 2004. Métodos de inventário: (1) levantamento em sítio de reprodução, (2) busca ativa. (*) Espécies cujos machos não foram encontrados em atividade de vocalização.

\begin{tabular}{ll}
\hline Espécie & Método \\
\hline
\end{tabular}

\section{Bufonidae}

Bufo abei Baldissera Jr., Caramaschi \& Haddad, 2004

Bufo ictericus Spix, 1824

Hylidae

Aplastodiscus albosignatus (A. Lutz \& B. Lutz, 1938)

Aplastodiscus ehrhardti (Müller, 1924)

Aplastodiscus perviridis Lutz in Lutz, 1950

Bokermannohyla circumdata (Cope, 1870)

Dendropsophus microps (Peters, 1872)

Dendropsophus minutus (Peters, 1872)

Dendropsophus nahdereri (B. Lutz \& Bokermann, 1963)

Hypsiboas albopunctatus (Spix, 1824)

Hypsiboas bischoffi (Boulenger, 1887)

Hypsiboas faber (Wied-Neuwied, 1821)

Hypsiboas prasinus (Burmeister, 1856)

Hypsiboas semiguttatus (A. Lutz, 1925)

Scinax catharinae (Boulenger, 1888)

Scinax fuscovarius (A. Lutz, 1925) *

Scinax perereca Pombal Jr., Haddad \& Kasahara, 1995

Scinax rizibilis (Bokermann, 1964)

Sphaenorhynchus surdus (Cochran, 1953)

Leptodactylidae

Adenomera marmorata Steindachner, 1867

Cycloramphinae

Cycloramphus bolitoglossus (Werner, 1897) *

Eleutherodactylus guentheri (Steindachner, 1864)

Eleutherodactylus sambaqui Castanho \& Haddad, 2000

Hylodes heyeri Haddad, Pombal Jr. \& Bastos, 1996

Leptodactylus notoaktites Heyer, 1978

Leptodactylus ocellatus (Linnaeus, 1758)

Physalaemus cuvieri Fitzinger, 1826

Physalaemus gracilis (Boulenger, 1883)

Physalaemus olfersii (Lichtenstein \& Martens, 1856)

Proceratophrys boiei (Wied-Neuwied, 1825)

Scythrophrys sawayae (Cochran, 1953)

Microhylidae

Chiasmocleis leucosticta (Boulenger, 1888) *

Ranidae

Rana catesbeiana Shaw, 1802

1,2

2

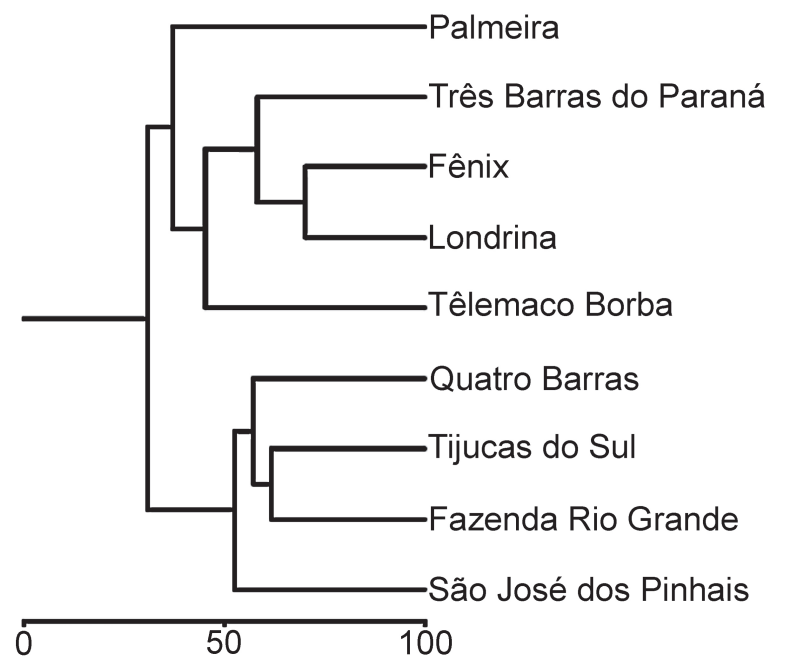

Figura 4. Similaridade (\%) na composição da anurofauna de nove localidades no estado do Paraná.

Bufo abei

B. ictericus

A. albosignatus

A. ehrhardti

A. perviridis

B. circumdata

D. microps

D. minutus

D. nahdereri

Hypsiboas albopunctatus

H. bichoffi

$H$ faber

H. prasinus

$H$. semiguttatus

Scinax catharinae

S. perereca

S. rizibilis

Sphaenorhynchus surdus Adenomera marmorata

Cycloramphinae n.d.

Hylodes heyeri

Eleutherodacty/us guenther

E. sambaqui

Leptodactylus notoaktites

$L$ ocellatus

P. cuvieri

P. gracilis

P. olfersii

Proceratophrys boiei

Scythrophrys sawayae Rana catesbeiana

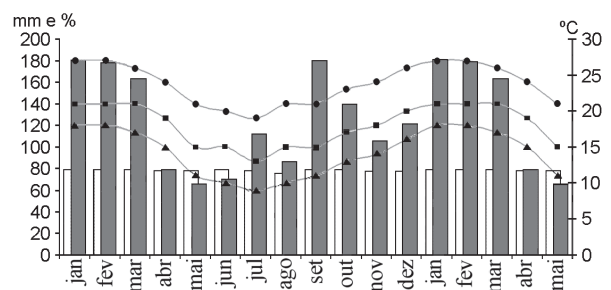

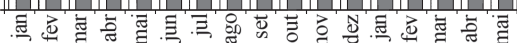
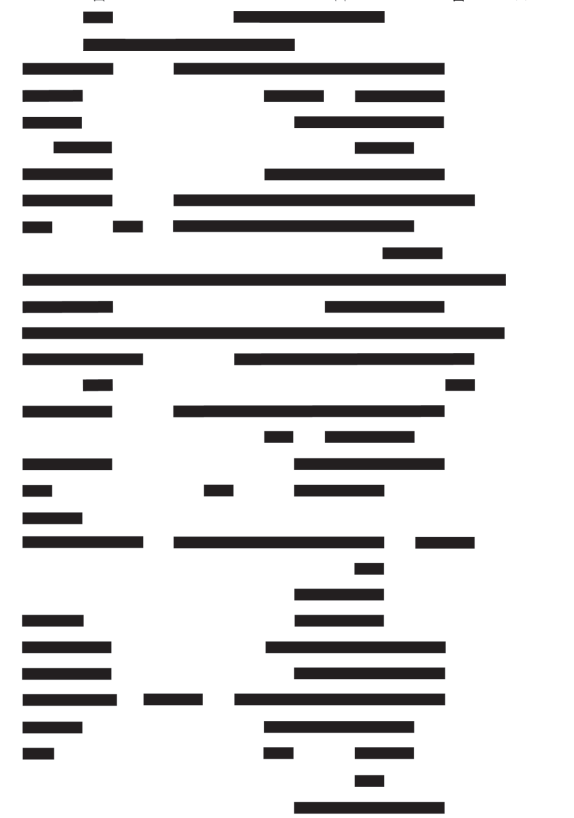

Figura 5. Valores médios de temperatura, umidade relativa e precipitação pluviométrica no período de 1998 a 2003, e período de atividade de vocalização das espécies de anfíbios anuros registradas em São José dos Pinhais, Paraná, entre janeiro de 2003 e maio de 2004.

Revista Brasileira de Zoologia 23 (1): 162-175, março 2006 

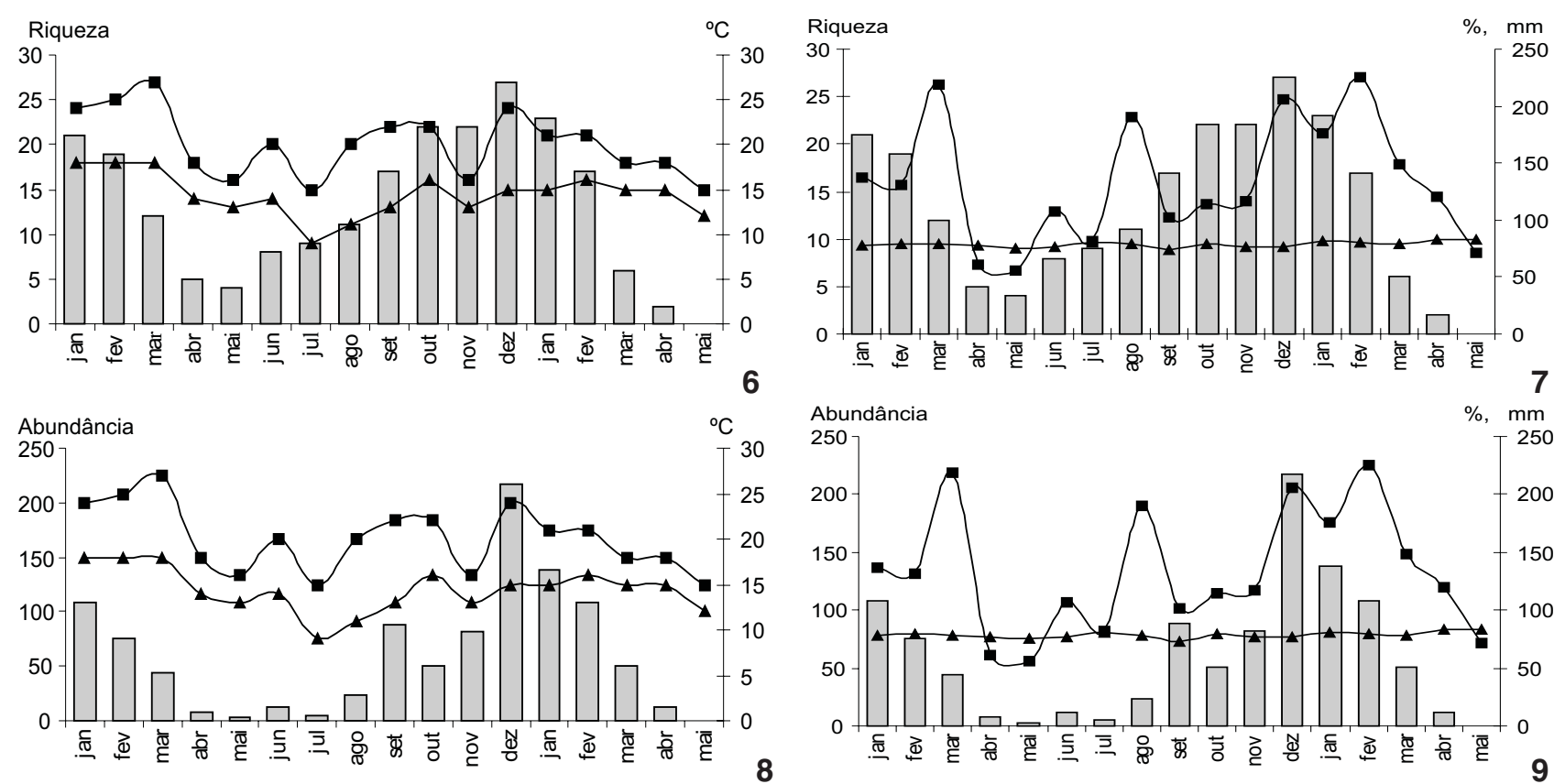

Figuras 6-9. (6-7) Riqueza de espécies (barras); (8-9) Abundância de machos em atividade de vocalização (barras). (6, 8)Temperatura do ar máxima $(\boldsymbol{\square})$ e mínima $(\boldsymbol{\Delta}),(7,9)$ precipitação mensal $(\boldsymbol{\square})$ e umidade relativa do ar $(\boldsymbol{\Delta})$, no período de janeiro de 2003 a abril de 2004, no município de São José dos Pinhais, Paraná.

Tabela IV. Diversidade (H'), diversidade teórica máxima (H'máx), porcentagem da diversidade teórica máxima (\% H'máx) e equitabilidade (e) nos nove corpos d'água amostrados em São José dos Pinhais, Paraná: (RF1) rio de leito pedregoso no interior de floresta, (RF2) continuação do rio de leito pedregoso em área plana, (RF3) córrego de leito pedregoso em interior de floresta, (RF4) riacho formado por nascente brejosa em interior de floresta, (RF5) riacho formado por nascente em interior de floresta, (TPG) tanque de piscicultura grande, (TPP) tanque de piscicultura pequeno, (PTF) poça temporária em interior de floresta, (PTA) poça temporária em área aberta.

\begin{tabular}{cccccc}
\hline Hábitats Número de espécies & $\mathrm{H}^{\prime}$ & H'máx. & \% H'máx. & $\mathrm{e}$ \\
\hline RF1 & 4 & 1,10 & 1,38 & 79 & 0,80 \\
RF2 & 9 & 1,86 & 2,19 & 84 & 0,84 \\
RF3 & 2 & 0,35 & 0,69 & 53 & 0,50 \\
RF4 & 4 & 1,23 & 1.60 & 77 & 0,76 \\
RF5 & 5 & 1,28 & 1,38 & 92 & 0,92 \\
TPG & 18 & 2,53 & 2,89 & 87 & 0,87 \\
TPP & 10 & 2,08 & 2,30 & 88 & 0,90 \\
PTF & 7 & 1,73 & 1,94 & 89 & 0,89 \\
PTA & 13 & 2,13 & 2,56 & 83 & 0,83 \\
\hline
\end{tabular}

cies apresentou atividade predominantemente noturna, com exceção de $H$. heyeri e Cycloramphinae n.d, que foram exclusivamente diurnas e Adenomera marmorata que vocalizou entre
16:00 e 22:00 h, aproximadamente. No mês de outubro, machos de $P$. cuvieri, $P$. gracilis e L. ocellatus vocalizaram durante o dia e à noite, sendo que os de P. cuvieri e L. ocellatus vocalizaram ininterruptamente ao longo do dia, enquanto os de $P$. gracilis iniciaram a atividade de vocalização por volta das 15:00 h. Nos meses restantes, a atividade de vocalização dessas espécies iniciava-se após o ocaso, entre 18:00 e 19:00 h. Machos de $D$. nahdereri e de $S$. perereca vocalizaram esporadicamente ao longo do dia durante todo o período estudado, porém, neste caso, somente em bromélias epífitas no interior da floresta.

Machos da maioria das espécies vocalizaram nos períodos de janeiro a fevereiro de 2003 e de setembro de 2003 a fevereiro de 2004, quando a temperatura e a precipitação foram mais elevadas (Figs 6-9). Em agosto, quando foi registrado um grande volume de chuva, fato inesperado para o período, várias espécies vocalizaram, mas em baixa abundância populacional (Figs 69). Em abril e maio de 2003 e de 2004, que foram os meses mais secos, foi registrado o menor número de espécies com machos em atividade de vocalização, sendo que em maio de 2004 nenhum macho vocalizou (Figs 6-9). O número de espécies em atividade de vocalização foi positivamente correlacionado com a temperatura máxima e com a precipitação pluviométrica mensal. Já a abundância de machos em atividade de vocalização foi correlacionada com as temperaturas máxima e mínima e com a precipitação mensal (Tab. VII).

De acordo com o período de vocalização, as espécies puderam ser classificadas em: 1) anuais, cujos machos vocalizaram 
Tabela V. Abundância das espécies registradas nos nove corpos d'água amostrados em São José dos Pinhais, Paraná.

\begin{tabular}{|c|c|c|c|c|c|c|c|c|c|}
\hline Espécies & RF1 & RF2 & RF3 & RF4 & RF5 & TGP & TPP & PTF & PTA \\
\hline Bufo abei & 0 & 1 & 0 & 0 & 0 & 14 & 5 & 0 & 0 \\
\hline Bufo ictericus & 0 & 0 & 0 & 0 & 0 & 2 & 0 & 0 & 0 \\
\hline Aplastodiscus albosignatus & 13 & 1 & 0 & 3 & 6 & 3 & 0 & 3 & 0 \\
\hline Aplastodiscus ehrhardti & 2 & 0 & 0 & 1 & 0 & 0 & 0 & 0 & 0 \\
\hline Aplastodiscus perviridis & 0 & 0 & 0 & 0 & 0 & 1 & 2 & 0 & 0 \\
\hline Bokermannohyla circumdata & 0 & 0 & 0 & 2 & 0 & 5 & 0 & 0 & 0 \\
\hline Dendropsophus microps & 0 & 0 & 0 & 0 & 2 & 1 & 8 & 9 & 11 \\
\hline Dendropsophus minutus & 0 & 0 & 0 & 0 & 0 & 11 & 7 & 0 & 10 \\
\hline Dendropsophus nahdereri & 0 & 0 & 0 & 0 & 0 & 3 & 0 & 0 & 2 \\
\hline Hypsiboas albopunctatus & 0 & 0 & 0 & 0 & 0 & 0 & 1 & 0 & 0 \\
\hline Hypsiboas bischoffi & 0 & 6 & 0 & 0 & 1 & 11 & 13 & 8 & 7 \\
\hline Hypsiboas faber & 0 & 0 & 0 & 0 & 0 & 2 & 2 & 0 & 1 \\
\hline Hypsiboas prasinus & 0 & 1 & 0 & 0 & 0 & 7 & 3 & 0 & 0 \\
\hline Hypsiboas semiguttatus & 0 & 12 & 0 & 0 & 0 & 2 & 0 & 0 & 0 \\
\hline Scinax catharinae & 0 & 7 & 0 & 0 & 16 & 0 & 0 & 11 & 0 \\
\hline Scinax perereca & 0 & 0 & 0 & 0 & 0 & 10 & 14 & 0 & 4 \\
\hline Scinax rizibilis & 0 & 0 & 0 & 0 & 0 & 3 & 0 & 2 & 3 \\
\hline Scinax surdus & 0 & 0 & 0 & 0 & 0 & 1 & 0 & 0 & 3 \\
\hline Cycloramphinae & 0 & 1 & 1 & 0 & 0 & 0 & 0 & 0 & 0 \\
\hline Hylodes heyeri & 16 & 1 & 8 & 0 & 0 & 0 & 0 & 0 & 0 \\
\hline Leptodactylus notoaktites & 0 & 0 & 0 & 0 & 0 & 0 & 0 & 0 & 5 \\
\hline Leptodactylus ocellatus & 0 & 0 & 0 & 0 & 0 & 2 & 0 & 0 & 3 \\
\hline Physalaemus cuvieri & 0 & 0 & 0 & 0 & 0 & 20 & 4 & 0 & 24 \\
\hline Physalaemus gracilis & 0 & 0 & 0 & 0 & 0 & 8 & 0 & 0 & 2 \\
\hline Physalaemus olfersii & 0 & 0 & 0 & 0 & 0 & 0 & 0 & 5 & 4 \\
\hline Physalaemus boiei & 0 & 4 & 0 & 1 & 4 & 0 & 0 & 1 & 0 \\
\hline Scythrophrys sawayae & 3 & 0 & 0 & 0 & 0 & 0 & 0 & 0 & 0 \\
\hline
\end{tabular}

Tabela VI. Similaridade na composição da anurofauna de nove localidades no estado do Paraná: (SJ) São José dos Pinhais (presente estudo); (FR) Fazenda Rio Grande (C.E. Conte obs. pess.); (TS) Tijucas do Sul (Conte \& MaChado 2005); (QB) Quatro Barras (Bernarde \& MAChado 2000); (TL) Telêmaco Borba (Rocha et al. 2003); (LO) Londrina, (TB) Três Barras do Paraná e (PA) Palmeira (BernaRDE \& MACHADo 2000); (FE) Fênix (MiKICH \& OLIVEIRA 2003). Números em negrito indicam o total de espécies em cada localidade e os sublinhados indicam o número de espécies em comum entre as localidades.

\begin{tabular}{|c|c|c|c|c|c|c|c|c|c|}
\hline Localidades & SJ & FR & TS & QB & $\mathrm{TL}$ & LO & $\mathrm{FE}$ & TB & PA \\
\hline SJ & 34 & 57 & 50 & 51 & 43 & 24 & 20 & 26 & 26 \\
\hline FR & $\underline{24}$ & 32 & 62 & 54 & 51 & 28 & 27 & 34 & 31 \\
\hline TS & $\underline{19}$ & $\underline{21}$ & 23 & 61 & 44 & 28 & 27 & 31 & 45 \\
\hline QB & $\underline{17}$ & $\underline{18}$ & $\underline{17}$ & 22 & 39 & 22 & 20 & 25 & 32 \\
\hline $\mathrm{TL}$ & $\underline{21}$ & $\underline{23}$ & $\underline{19}$ & $\underline{17}$ & 39 & 50 & 38 & 47 & 45 \\
\hline LO & $\underline{12}$ & $\underline{13}$ & $\underline{11}$ & $\underline{9}$ & $\underline{22}$ & 27 & 70 & 66 & 31 \\
\hline $\mathrm{FE}$ & $\underline{9}$ & $\underline{11}$ & $\underline{9}$ & $\underline{7}$ & $\underline{16}$ & $\underline{19}$ & 20 & 50 & 36 \\
\hline TB & $\underline{12}$ & $\underline{13}$ & $\underline{11}$ & $\underline{9}$ & $\underline{20}$ & $\underline{20}$ & $\underline{14}$ & 23 & 35 \\
\hline PA & 11 & $\underline{12}$ & $\underline{13}$ & $\underline{10}$ & $\underline{18}$ & 11 & $\underline{10}$ & 11 & 19 \\
\hline
\end{tabular}

Revista Brasileira de Zoologia 23 (1): 162-175, março 2006 
Tabela VII. Correlação da riqueza de espécies e abundância de machos em atividade de vocalização com alguns parâmetros climáticos da área estudada em São José dos Pinhais, Paraná.

\begin{tabular}{lcccccc}
\hline \multirow{2}{*}{ Parâmetros climáticos } & \multicolumn{2}{c}{ Riqueza } & & \multicolumn{2}{c}{ Abundância } \\
\cline { 2 - 3 } \cline { 6 - 7 } & $\mathrm{rs}$ & $\mathrm{p}$ & & $\mathrm{rs}$ & $\mathrm{p}$ \\
\hline Temperatura mínima & 0,36 & 0,160 & & 0,56 & 0,010 \\
Temperatura máxima & 0,63 & 0,008 & & 0,69 & 0,002 \\
Umidade relativa do ar & $-0,29$ & 0,260 & & $-0,09$ & 0,710 \\
Precipitação & 0,51 & 0,030 & & 0,68 & 0,002 \\
\hline
\end{tabular}

ao longo do ano (Aplastodiscus albosignatus, Dendropsophus minutus, Hypsiboas bischoffi, $H$. prasinus, $H$. semiguttatus, $S$. perereca, Hylodes heyeri, Physalaemus gracilis); 2) de início de estação chuvosa, cujos machos vocalizaram apenas no início dessa estação (Leptodactylus notoaktites); 3) de estação chuvosa, cujos machos vocalizaram na época mais quente e chuvosa do ano (Bufo abei, Aplastodiscus ehrhardti, A. perviridis, Bokermannohyla circumdata, Dendropsophus microps, D. nahdereri, H. albopunctatus, $H$. faber, Scinax rizibilis, Sphaenorhynchus surdus, Cycloramphinae n.d., Eleutherodactylus sambaqui, Leptodactylus ocellatus, Physalaemus cuvieri, P. olfersii e Rana catesbeiana); 4) esporádicas, cujos machos vocalizaram apenas após chuvas fortes, ao longo de todo o todo o ano (Adenomera marmorata) ou na estação quente e chuvosa (Scinax catharinae, Eleutherodactylus guentheri, Proceratophrys boiei e Scythrophrys sawayae); 5) de estação fria, cujos machos vocalizaram preponderantemente no período mais seco e frio (Bufo ictericus) (Fig. 5).

\section{DISCUSSÃO}

\section{Diversidade de espécies}

Com o método de levantamento em sítio de reprodução foi possível encontrar 79\% das 34 espécies registradas. Em quatro corpos d'água, o método de extrapolação indicou que mais espécies poderiam ser encontradas, o que pode ser explicado pelo fato deste método ser pouco eficiente para o registro de espécies com reprodução explosiva e/ou hábitos fossoriais que vocalizam em poucos dias do ano, como Chiasmocleis leucosticta (HADDAD \& HöDl 1997) e Cycloramphus bolitoglossus (HEYER 1983, Verdade \& Rodrigues 2003). Isso evidencia a importância de empregar métodos complementares como busca ativa que, no presente estudo, possibilitou o registro de 20 espécies, das quais sete exclusivamente por esse método.

A diversidade tem sido medida através da aplicação de vários índices (MagurRAN 1988, KRebs 1999), que integram a riqueza de espécies e a equitabilidade na abundância populacional (KReBS 1999). A riqueza de espécies de anuros registrada em São José dos Pinhais é a segunda maior do estado, correspondendo a $28 \%$ da anurofauna conhecida no Paraná (Tab. VIII), e a diversidade foi considerada alta em oito dos nove ambientes amos- trados. A grande riqueza e diversidade de espécies pode ser atribuída ao fato da área estudada estar localizada em uma região de ecótono. Nesta área, foram encontrados animais típicos da Floresta Ombrófila Densa, como E. sambaqui, H. heyeri, S. sawayae e C. leucosticta (CASTANHO \& HADDAD 2000, LingNAU 2000, Segalla \& Langone 2004, Frost 2004), e da Floresta Ombrófila Mista, como H. semiguttatus e S. catharinae (KwEt \& Di-BERNARdo 1999), além de espécies típicas de área aberta, como B. ictericus, D. minutus, $H$. albopunctatus, L. ocellatus, $P$. cuvieri e $P$. gracilis (Cei 1980, Heyer et al. 1990, Haddad \& Sazima 1992, Machado et al. 1999). Além disso, uma explicação adicional para essa alta diversidade é a hipótese do distúrbio intermediário (ConNelL 1978), cujo foco principal está na freqüência e intensidade de distúrbios que afetam os padrões de diversidade (Morin 1999). Com um nível moderado de perturbação a comunidade se distribui em um mosaico de partes de hábitats, favorecendo a ocorrência de alta diversidade de espécies (Huston 1994, PIANKA 1994, RICKLEFS 2003). Na localidade estudada houve corte seletivo de árvores até trinta anos atrás, para exploração de madeira. Desde então está em processo de regeneração natural, com pequeno impacto decorrente do desmatamento de pequenas áreas para estabelecimento de chácaras de lazer. Assim, com esse longo período de regeneração, a conversão de pequenas áreas dessa floresta para áreas abertas pode ser considerada como um distúrbio intermediário que, possibilitando a ocorrência de algumas espécies típicas de áreas abertas como $H$. albopunctatus e D. minutus, aumenta a riqueza de espécies local.

A anurofauna de São José dos Pinhais é composta, em sua maioria, por espécies das famílias Hylidae (50\%) e Leptodactylidae (38\%). A mesma proporção foi observada em outras 18 localidades do bioma Floresta Atlântica (Tab. VIII). Apenas em Boracéia (Heyer et al. 1990) e Três Barras do Paraná (Bernarde \& Machado 2000) as espécies de Leptodactylidae representaram maior proporção da anurofauna. Esse padrão pode ser conservativo ou resultar de pressões ecológicas recentes, porém, a elucidação dos padrões atuais de distribuição não é simples. Somente o conhecimento, em diferentes graus, de fatores históricos e ecológicos para cada espécie em particular permitiria elucidar essas questões (Vuilleumier \& Simberloff 1980).

Estudos dos padrões de distribuição de anuros têm revelado a influência dos domínios morfoclimáticos na composição da anurofauna (CRUMP 1971, HeYER 1988). A comparação da anurofauna de diversas localidades do estado do Paraná evidenciou a importância dos domínios morfoclimáticos na distribuição das espécies. A similaridade na composição da anurofauna de Quatro Barras, Tijucas do Sul, Fazenda Rio Grande e São José dos Pinhais pode ser explicada pelo fato destes municípios estarem localizadas nos domínios da Floresta Ombrófila Mista e na transição desta para Floresta Ombrófila Densa. Apesar do grau variado de desmatamento nessas localidades, essa região é caracterizada por ausência de período seco, com precipitação abundante e bem distribuída ao longo do ano (Ibge 1992). Por outro lado, Três Barras do Paraná, Londrina e 
Tabela VIII. Lista de localidades com levantamentos da anurofauna nos domínios da Floresta Atlântica latu sensu. (FOD) Floresta Ombrófila Densa, (FES) Floresta Estacional Semidecídua, (FOM) Floresta Ombrófila Mista.

\begin{tabular}{|c|c|c|c|c|c|c|}
\hline \multirow[t]{2}{*}{ Localidade } & \multirow{2}{*}{ Sub-formação } & \multirow{2}{*}{$\begin{array}{l}\text { Período } \\
\text { amostrado }\end{array}$} & \multirow{2}{*}{$\begin{array}{c}\text { Número } \\
\text { de } \\
\text { espécies }\end{array}$} & \multicolumn{2}{|c|}{$\begin{array}{l}\text { Número (\%) de espécies } \\
\text { das famílias }\end{array}$} & \multirow{2}{*}{ Referências } \\
\hline & & & & s Hylidae & Leptodactylidae & \\
\hline Estação Biológica de Boracéia, SP & FOD & $>5$ anos & 66 & $29(43)$ & $30(46)$ & HEYER et al. (1990) \\
\hline Santuário Ecológico Serra do Japi, SP & FES/FOD & 12 meses & 24 & $11(46)$ & $9(37)$ & HADDAD \& SAZIMA (1992) \\
\hline Serra de Paranapiacaba, SP & FOD & 12 meses & 19 & $11(57)$ & $6(31)$ & POMBAL JR. (1997) \\
\hline Parque Estadual do Rio Doce, MG & FOD & $>5$ anos & 38 & $22(57)$ & $9(23)$ & Feıo et al. (1998) \\
\hline Município: Guararapes, SP & FES & 28 meses & 26 & $11(42)$ & $11(42)$ & Bernarde \& KoKubum (1999) \\
\hline Parque Estadual Rio Guarani, PR & FES & 12 meses & 23 & 9 (39) & $10(43)$ & BeRNARDE \& Machado (2000) \\
\hline Município: Quatro Barras, PR & FOD & 12 meses & 22 & $13(59)$ & $6(27)$ & BeRNARDE \& MACHADO (2000) \\
\hline Parque Estadual Intervales, SP & FOD & 12 meses & 48 & $25(52)$ & $18(37)$ & BertoluCi (2001) \\
\hline Estação Biológica Boracéia, SP & FOD & 13 meses & 28 & $18(64)$ & $8(28)$ & Bertoluci \& Rodrigues (2002) \\
\hline Fazenda Monte Alegre, PR & FOM/FES & 48 meses & 39 & $22(56)$ & $12(31)$ & Rocha et al. (2003) \\
\hline Município: Londrina, PR & FES & 24 meses & 27 & $11(40)$ & $11(40)$ & MACHADO \& BeRNARDE (2002) \\
\hline Estação Ecológica Juréia-Itatins, SP & FOD & 10 meses & 26 & $15(57)$ & $7(26)$ & POMBAL JR. \& GORDO (2004) \\
\hline APA de Guaiapaba-Açu, ES & FOD & 24 meses & 41 & $24(58)$ & $12(17)$ & Ramos \& Gasparine (2004) \\
\hline Município: Fazenda Rio Grande, PR & FOM & 15 meses & 32 & $18(56)$ & $11(34)$ & C.E. Conte, obs. pess. \\
\hline Município: Tijucas do Sul, PR & FOM & 13 meses & 23 & $13(56)$ & $8(34)$ & Conte \& MACHADo (2005) \\
\hline Parque Vila Rica Espirito Santo, PR & FES & 12 meses & 19 & $10(52)$ & $6(31)$ & MIKICH \& OLIVEIRA (2003) \\
\hline Município: Rio de Janeiro, RJ & FOD & $>5$ anos & 69 & $33(47)$ & $22(31)$ & IZECKsohn \& CaRVAlho-e-Silva (2001) \\
\hline $\begin{array}{l}\text { Centro de Pesquisa e Conservação } \\
\text { da Natureza - Pró-Mata, RS }\end{array}$ & FOM & 48 meses & 36 & $19(52)$ & $12(33)$ & KWET \& Di-BerNARDo (1999) \\
\hline
\end{tabular}

Fênix estão localizadas em região originalmente recoberta por Floresta Estacional Semidecidual, cujo clima pode ser caracterizado por apresentar estação seca definida, quando 20 a $50 \%$ das árvores perdem suas folhas (Veloso et al. 1991, RoderJan et al. 2002). Telêmaco Borba está localizada em área de ecótono entre Floresta Ombrófila Mista, Floresta Estacional Semidecidual e Campos Naturais, apresentando uma fauna constituída de espécies típicas das três formações, que se reflete na maior riqueza de espécies e nos valores de similaridade próximos a 0,50 na composição da anurofauna deste município com a daquelas inseridas nos domínios da FOM, FOD e de Campos Naturais (ver Tabs II e IV). A menor similaridade na composição da anurofauna de Palmeira com a das demais localidades decorre, provavelmente, da influência da formação vegetal de pequeno porte, constituída por Campos Naturais, típica desta localidade (Bernarde \& Machado 2000).

\section{Sazonalidade}

Diversos estudos (e.g. Duellman \& Trueb 1986, Rossa-Feres \& Jim 1994, Arzabe 1999, Prado et al. 2004, Vasconcelos \& RossaFERES 2005) demonstraram que a atividade reprodutiva dos anfíbios anuros é fortemente influenciada por fatores abióticos. Em São José dos Pinhais, a maioria das espécies (48\%) ocorreu na estação chuvosa, enquanto as anuais representaram $25 \%$ da anurofauna. As baixas temperaturas características das regiões brasileiras abaixo do Trópico de Capricórnio, onde a ocorrência de geadas severas é freqüente ao longo dos meses de abril a setembro (MAACK 1981), inibiram a atividade de vocalização das espécies em abril e maio de 2003 e de 2004. Por outro lado, a região recebe grande volume de precipitação pluviométrica e não apresenta estação seca definida (PARANá 1987). Espécies anuais são comuns em ambientes com clima tropical úmido (Duelmann \& Trueb 1986), como em Santa Cecilia, Equador, onde CRump (1974) e Duellman (1978) registraram grande número de espécies com reprodução ao longo do ano (cerca de 33\% e 30\%, respectivamente). Em regiões sazonais, com estação seca definida, Arzabe (1999), Toledo et al. (2003), Prado et al. (2004) e VAsconcelos \& Rossa-Feres (2005), registraram menor proporção de espécies anuais $(0 \%, 0 \%, 12,5 \%$ e 7,4\%, respectivamente), com predomínio daquelas associadas à estação chuvosa (100\%, 80\%, 50\% e 92,6\%, respectivamente). Diversos estudos indicam que em ambientes sazonais, principalmente em relação à chuva, a maioria das espécies se reproduz na estação chuvosa (Duellman 1978, Aichinger 1987, Rossa-Feres \& Jim 1994). Assim, o padrão de distribuição da anurofauna de São José dos Pinhais pode ser considerado intermediário entre o encontrado em regiões sazonais e em regiões tropicais úmidas. Em outra área de Floresta Atlântica, Boracéia, São Paulo, Bertoluci \& RoDRIGUEs (2002), registraram uma proporção de espécies anuais de apenas 11\%. Entretanto, segundo Bertoluci \& Heyer 
(1995), o volume anual de chuvas nessa região tem diminuído e o clima vem se tornando progressivamente mais árido. Essa aridez pode explicar a menor proporção de espécies anuais em Boracéia. Esses resultados conflitantes para áreas de Floresta Atlântica indicam que, mais que a fisionomia vegetal, o volume e a distribuição das chuvas regulam a distribuição sazonal das espécies de anuros.

\section{CONSIDERAÇÕES FINAIS}

A anurofauna estudada representa, até o momento, a segunda maior riqueza de espécies do estado do Paraná. O método de levantamento em sítio de reprodução foi eficiente, porém foi evidenciada a importância da utilização de métodos complementares, para amostragem de espécies de reprodução explosiva ou de hábitos fossoriais. A grande diversidade de espécies encontrada pode ser explicada tanto pelo fato da área estar localizada em ecótono entre FOM e FOD quanto pela hipótese do distúrbio intermediário. $\mathrm{Na}$ área estudada, o distúrbio ocorreu pela supressão de pequenas áreas florestais, que criou novos espaços para colonização de espécies adaptadas a áreas abertas. Entretanto o impacto deste desmatamento foi minimizado pela regeneração da floresta ocorrida nos últimos 30 anos, o que criou um mosaico de hábitats que comportam espécies florestais e de área aberta. A distribuição temporal das espécies foi influenciada tanto pelo regime de chuvas quanto pela temperatura: machos da maioria das espécies vocalizaram no período mais chuvoso e quente do ano, mas a proporção de espécies anuais foi grande, semelhante à encontrada em regiões com clima tropical úmido.

\section{AGRADECIMENTOS}

A Bruno V.S. Pimenta, Célio F.B. Haddad, Oswaldo L. Peixoto, Vanessa K. Verdade pela identificação de espécies. A Rodrigo Lingnau e Solange Aranha pela tradução do resumo e a Gledson V. Bianconi pelas críticas e contribuições na versão preliminar. Ao IBAMA pela autorização de coleta (Licença n ${ }^{\circ}$. 099/2003). A Fundação de Amparo à Pesquisa do Estado de São Paulo, no âmbito do programa BIOTA/FAPESP (Processo $n^{\circ}$ 01/13341-3) e à Coordenação de Aperfeiçoamento de Pessoal de Nível Superior CAPES pela bolsa concedida a C.E.C., junto ao Programa de Pósgraduação em Biologia Animal, UNESP, São José do Rio Preto.

\section{REFERÊNCIAS BIBLIOGRÁFICAS}

Alford, A.R. \& S.J. Richards. 1999. Global amphibian declines: a problem in applied ecology. Annual review of ecology, evolution, and systematics, Califórnia, 30: 133-165.

AICHINGER, M. 1987. Annual activity patterns of anurans in a seazonal neotropical environment. Oecologia, Berlim, 71: 583-592.

ArZABE, C. 1999. Reproductive activity patterns of anurans in two different altitudinal sites within the Brazilian Caatinga. Revista Brasileira de Zoologia, Curitiba. 16 (3): 851-864.
BeEbeE, T.J.C. 1996. Ecology and conservation of amphibians. London, Chapman \& Hall, VII+214p.

Bernarde, P.S. \& M.N.C. Kokubum. 1999. Anurofauna do Município de Guararapes, Estado de São Paulo, Brasil (Amphibia, Anura). Acta Biologica Leopoldensia, São Leopoldo, 21: 89-97.

Bernarde, P.S. \& R.A. Machado. 2000. Riqueza de espécies, ambientes de reprodução e temporada de vocalização da anurofauna em Três Barras do Paraná, Brasil (Amphibia: Anura). Cuadernos del Herpetologia, Tucumán, 14 (2): 93 104.

BerTOLUCI, J. 2001. Anfíbios anuros, p. 158-167. In: C. LeONEL (Ed.). Intervales: fundação para a conservação e a produção florestal do estado de São Paulo. São Paulo, Centro de Editoração, Secretaria de estado do meio ambiente, IX+231p.

Bertoluci, J. \& W.R. Heyer. 1995. Boracéia Update. Froglog Newsletter of the World Conservation Union, Species Survival Commission Declining Amphibian Populations Task Force, Reino Unido, 14: 2-3.

Bertoluci, J. \& M.T. Rodrigues. 2002. Seasonal patterns of breeding activity of Atlantic Rainforest anurans at Boracéia, Southeastern Brazil. Amphibia-Reptilia, Leiden, 23 (2): 161-167.

Castanho, L. \& C.F.B. Haddad. 2000. New species of Eleutherodactylus (Amphibia: Leptodactylidae) from Guaraqueçaba, Atlantic Forest of Brazil. Copeia, Lawrence, 33 (3): 777-781.

CeI, J.M. 1980. Amphibians of Argentina. Monitore Zoologico Italiano, (N. S.), Monografia, 2, XII+609p.

Colwell, R.K. 2001. Estimates: statistical estimation of species richness and shared species from samples. Version 6.0.b1. User's Guide and application published at: http://viceroy. eeb.uconn.edu/estimates.

Colwell, R.K. \& J.A. Coddington. 1994. Estimating terrestrial biodiversity through extrapolation. Phylosophical transactions of the Royal Society of London 345: 101118.

Connell, J.H. 1978. Diversity in tropical rainforests and coral reefs. Science, Washington, 199: 1302-1310.

Conte C.E. \& R.A. Machado. 2005. Riqueza de espécies e distribuição espacial e temporal em comunidade de anfíbios anuros (Amphibia, Anura) em uma localidade de Tijucas do Sul, Paraná, Brasil. Revista Brasileira de Zoologia, Curitiba, 22 (4): 940-948.

Crump, M.L. 1971. Quantitative analysis of the ecological distribition of a tropical herpetofauna. Occasional papers of the Museum of Natural History the University of Kansas, Lawrence, 3: 1-62.

Crump, M.L. 1974. Reprodutive strategies in a tropical anuran community. Miscellaneous publications Natural History University Kansas, Lawrence, 61: 1-68.

Duellman, W.E. 1978. The biology of an equatorial herpetofauna in Amazonian Ecuador. Micellaneous publication Museum Natural History University of Kansas, Lawrence, Kansas, 65: $1-352$.

Revista Brasileira de Zoologia 23 (1): 162-175, março 2006 
Duellman, W.E. 1990. Herpetofaunas in neotropical rainforests: comparative composition, history, and resource use, p. 455505. In: A.H. Centry (Ed.) Four Neotropical Rainforests. New Haven, Yale University Press, XI+627p.

Duellman, W.E. 1999. Global distribution of amphibians: patterns, conservation, and future challenges, p. 1-31. In: W. E. Duellman (Ed.). Patterns of distribution of amphibians: a global perspective. Baltimore \& London, The John Hopkins University, VII+648p.

Duellman, W.E. \& L. Trueb. 1986. Biology of amphibians. New York, McGraw-Hill Book Company, 670p.

Embrapa. 1996. Atlas do meio ambiente do Brasil. Brasília, Serviço de Produção e Informação, Terra Viva, 160p.

Feio, R.N.; U.M.L. Braga; H. Wiederhecker \& P.S. Santos. 1998. Anfíbios do Parque Estadual do Rio Doce (Minas Gerais). Viçosa, Universidade Federal de Viçosa, Instituto Estadual de Florestas, 32p.

Ferreira, J.C.V. 1996. O Paraná e seus municípios. Maringá, Memória Brasileira, 728p.

Frost, D.R. 2004. Amphibian Species of the world: an online reference. Version 3.0 (22 August, 2004). Electronic Database available at: http://research.amnh.org/ herpetology/amphibia/index.php

Fundação SOS Mata Atlântica. 1998. Atlas da Evolução dos remanescentes florestais e ecossistemas associados do domínio da Mata Atlântica no período de 1990 -1995. Relatório Nacional. São Paulo, Fundação SOS Mata Atlântica, Instituto Nacional de Pesquisas Espaciais, Instituto Sócio-Ambiental, 7p.

HadDad, C.F.B. \& I. SAzima. 1992. Anfíbios anuros da Serra do Japi, p. 188-211. In: L.P.C. Morellato (Ed.). História Natural da Serra do Japi. Campinas, Editora da UNICAMP, FAPESP, 321p.

HadDad, C.F.B. \& W. HödL.1997. New reproductive mode in anurans: buble nest in Chiasmocleis leucosticta (Microhylidae). Copeia, Lawrence, 3: 585-588.

Heyer, W.R. 1983. Variation and sistematics of frogs of the genus Cycloramphus (Amphibia, Leptodactylidae). Arquivos de Zoologia, São Paulo, 30: 235-39.

Heyer, W.R. 1988. On frog distribution pattrens east of the Andes, p. 254-274. In: P.E. Vanzolini \& W.R. Heyer (Eds). Proceedings of a Workshop on Neotropical Distribution Patterns. Rio de Janeiro, Academia Brasileira de Ciências, 448p.

Heyer, W.R.; A.S. Rand; C.A.G. Cruz, O.L. Peixoto \& C.E. Nelson. 1990. Frogs of Boracéia. Arquivos de Zoologia, São Paulo, 31 (4): 231-410.

Huston, M.A. 1994. Biological diversity - the coexistence of species on changing landascapes. New York, Cambridge Univesity Press, XIX+681p.

IвGE. 1992. Manual técnico da vegetação brasileira. Rio de janeiro, Fundação Instituto Brasileiro de Geografia e Estatística, Manuais Técnicos de Geociências, $n^{\circ} 1,92 \mathrm{p}$.
Izecksohn, E. \& S.P. Carvalho-e-Silva. 2001. Anfíbios do Município do Rio de Janeiro. Rio de Janeiro, Editora UFRJ, 147p.

KREBS, C.J. 1999. Ecological methodology. Menlo Park, Addison Wesley Longman, 620p.

Kwet, A. \& M. Di-Bernardo. 1999.Anfíbios, Amphibien, Amphibians. Rio Grande do Sul, EDIPUCRS, II+108p.

LingnaU, R. 2000. Geographic distribution. Hylodes heyeri. Herpetological Review, Lawrence, 31 (3): 251-251.

MAACK, R. 1981. Geografia física do estado do Paraná. Rio de Janeiro, José Olympio, Secretaria da Cultura e do Esporte do Governo do Estado do Paraná, XLIII+442p.

Machado, R.A. \& P.S. Bernarde. 2002. Anurofauna da bacia do rio Tibagi, p. 297-306. In: M.E. Medri; E. Bianchini; O.A. Shibatta \& J.A. Pimenta (Eds). A Bacia do Rio Tibagi. Londrina, Edição dos editores, 595p.

Machado, R.A.; P.S. Bernarde; S.A.A. Morato \& L. Anjos. 1999. Análise comparada da riqueza de anuros entre duas áreas com diferentes estados de conservação no município de Londrina, Paraná, Brasil (Amphibia, Anura). Revista Brasileira de Zoologia, Curitiba, 16 (4): 997-1004.

MagurRan. A. 1988. Ecological diversity and its measurement. New Jersey, Princeton University Press, X+179p.

Mikich, S.B. \& K.L. Oliveira. 2003. Revisão do Plano de Manejo do Parque Estadual Vila Rica do Espírito Santo, Fênix - PR. Curitiba, Mater Natura, Instituto de Estudos Ambientais, Ministério do Meio Ambiente, Fundo Nacional do Meio Ambiente, 452p.

Morin, P.J. 1999. Community ecology. New Jersey, Blackwell Science, VII+424p.

Myers, N.; R.A. Mittermeyer; C.G. Mittermeyer; G.A.B. Fonseca \& J. Kent. 2000. Biodiversity hot spots for conservation priorities. Nature, London, 403: 853-858.

Paraná. 1987. Atlas do Estado do Paraná. Secretaria de Estado da Agricultura e do Abastecimento, Instituto de Terras, Cartografia e Florestas, Curitiba, XI+73p.

PIANKA, E.R. 1994. Evolutionary ecology. New York, Harper Collins College Publishers, IX+486p.

Pombal JR., J.P. 1997. Distribuição espacial e temporal de anuros (Amphibia) em uma poça permanente na Serra de Paranapiacaba, Sudeste do Brasil. Revista Brasileira de Biologia, Rio de Janeiro, 57: 583-594.

Pombal Jr. \& M. Gordo. 2004. Anfíbios anuros da Juréia, p. 243256. In: O.V. MARQues \& D. WÂNIA, (Eds). Estação Ecológica Juréia-Itatins. Ambiente Físico, Flora e Fauna. Ribeirão Preto, Holos, 386p.

Prado, C.P.A.; M. Uetanabaro \& C.B.F. Haddad. 2004. Breeding activity patterns, reprodustive modes, and habitats use by anurans (Amphibia) in a seazonal enviromental in the Panatanal, Brazil. Amphibia-Reptilia, Leiden, 26 (2): 211-221.

Ramos, A.D. \& J.L. Gasparine. 2004. Anfíbios do GuaiapabaAçu. Vitória, Santo Antônio, 75p.

RiCKLEFs, R.E. 2003. A economia da natureza. Rio de Janeiro, Guanabara Koogan, XXIII+503p. 
Rocha, V.L; R.A. Machado, S.A. Filipaki; I.S.N. Fier \& J.A.L. Pucci. 2003. A biodiversidade da Fazenda Monte Alegre da Klabin S/A - no estado do Paraná. In: Anais VIII Congresso Florestal Brasileiro, São Paulo, vol. 2, p. 1-12.

Roderjan, C.V.; F. Galvão; Y.S. Kuniyoshi \& G.G. Hatschbach. 2002. As unidades fitogeográficas do Estado do Paraná, Brasil. Revista \& Ambiente, Santa Maria, 24: 78-118.

Rossa-Feres, D.C. \& J. Jim. 1994. Distribuição sazonal em comunidade de anfíbios anuros na região de Botucatu, São Paulo. Revista Brasileira de Biologia, Rio de Janeiro, 54 (2): 323334.

SANTOS, A.J. 2003. Estimativas de riqueza em espécies, p. 19-41. In: L. Cullen Jr.; R. Rudran \& C.V. Padua (Eds). Métodos de estudos em biologia da conservação e manejo da vida silvestre. Curitiba, Editora da UFPR, Fundação O Boticário de Proteção à Natureza, 665p.

Segala, M.V. \& J.A. Langone. 2004. Anfíbios, p. 537-577. In: S. B. Мiкich \& R.S. Bérnils (Eds). Livro vermelho da fauna ameaçada no estado do Paraná. Curitiba, Instituto Ambiental do Paraná, XVI+764p.

ScotT JR., N.J. \& B.D. WoodWARd. 1994. Survey at breeding sites, p. 118-125. In: W.R. Heyer; M.A. Donnelly; R.W. McDiarmid; L.A.C. Hayek \& M.S. Foster. (Eds). Measuring and monitoring biological diversity - standard methods for amphibians. Washington, Smithsonian Institution Press, XIX+364p.

Tocher, M.D.; G. Gascon \& B.L. Zimmerman. 1997. Fragmentation effects on a Central Amazonian frog community: a ten-year study, p. 124-127. In: W.F. LaURenCE \& R.O. BierRegaARd (Eds).
Tropical forest remnants: ecology, management, and conservation of fragmented communities. London, The University of Chicago Press, XI+616p.

Toledo, L.F; J. ZINA \& C.F.B. HADDAD. 2003. Distribuição espacial e temporal de uma comunidade de anfíbios anuros do Município de Rio Claro, São Paulo, Brasil. Holos Environment, Rio Claro, 3 (2): 136-149.

Vasconcelos, T.S. \& D.C. Rossa-Feres. 2005. Diversidade, distribuição espacial e temporal de anfíbios anuros (Amphibia, Anura) na região noroeste do Estado de São Paulo, Brasil, Biota Neotropica, São Paulo, 5 (2). Disponível na World Wide Web em: http://www.biotaneotropica.org.br/v5n2/pt/ abstract?article+BN01705022005 [Acesso em 10.IX.2005].

Veloso, H.P.; A.L.R. Rangel-Filho \& J.C.A. Lima. 1991. Classificação da vegetação brasileira, adaptada a um sistema universal. Rio de Janeiro, IBGE, Departamento de Recursos Naturais e Estudos Ambientais, 124p.

Verdade, V.K. \& M.T. Rodrigues. 2003. A new species of Cycloramphus (Anura, Leptodactylidae) from the Atlantic Forest, Brazil. Herpetologica, Lafayette 59 (4): 515-520.

Vuilleumier, F. \& D. Simberloff. 1980. Ecology versus history as determinants of patchy and insular distributions in high Andean Birds, p. 235-379. In: M. Hecht; W.C. SteERE, \& B. Wallace (Eds). Evolutionary Biology. New York, Plenum Publishing Corporation, 514p.

Wilson, E.O. 1988. Biodiversity. Washington, National Academy Press, XIII+521p.

ZAR, J.H. 1984. Bioestatistical Analysis. New Jersey, Prentice Hall, 663p.

Recebido em 02.III.2005; aceito em 23.I.2006. 